\title{
Does smallholder farmers' awareness of Sustainable Development Goal 2 improve household food security in the Northern Region of Ghana?
}

\author{
Franklin Nantui Mabe ${ }^{1 *}$ (D) Eliasu Mumuni ${ }^{2}$ and Nashiru Sulemana ${ }^{3}$
}

\begin{abstract}
Background: Sustainable Development Goal 2 aims at ending hunger, achieving food security, improving nutrition and promoting sustainable agriculture. Whilst some smallholder farmers are aware of this goal, others are not. The question that arises is whether or not awareness translates into food security. Therefore, this study assessed whether or not smallholder farmers' awareness of Sustainable Development Goal 2 improves household food security in the Northern Region of Ghana.

Methods: The study used cross-sectional primary data collected from two districts and two municipalities in the region. An endogenous switching regression treatment effects model with ordered outcome was used to estimate the effects of smallholder farmers' awareness of Sustainable Development Goal 2 on household food insecurity level.

Results: The age of household head, distance of households to the regional capital, membership of farmer-based organizations, access to e-extension, education, and ownership of radio are the key drivers of farmers' awareness of Sustainable Development Goal 2. The results from the endogenous switching regression treatment effects model with ordered outcome showed that households who are aware of the second goal are more food secure than their counterparts.
\end{abstract}

Conclusions: It is therefore prudent for stakeholders promoting and championing Sustainable Development Goals to educate farmers on goal 2 as their awareness of the goal is critical to achieving food security.

Keywords: Awareness, Food Insecurity Experience Scale and Sustainable Development Goal 2, Smallholder farmers

\section{Background}

As noted by [1], the higher education a household head attains, the more he or she is well informed and aware of the available improved agricultural technologies, thereby adopting them to enhance household food supply. The adoption of the 2030 agenda for sustainable development

\footnotetext{
${ }^{*}$ Correspondence: mfnantui@uds.edu.gh

${ }^{1}$ Department of Agricultural and Resource Economics, Faculty

of Agribusiness and Applied Economics, University for Development Studies, Tamale, Ghana

Full list of author information is available at the end of the article
}

by Heads of States and Governments around the world took place in September 2015 at the United Nations Headquarters. Irrespective of the massive use of the term sustainable development, over the years, the concept still seems vague as many people continue to do not know its meaning and history [2]. The adoption of agenda 2030 which talks about the Sustainable Development Goals (SDGs) has compounded the problem. The 2030 agenda on sustainable development is a plan of action that consists of 17 SDGs. All the Heads of States and Governments are mandated to implement policies and programmes that aim at achieving the 17 SDGs in the

(c) The Author(s) 2021. This article is licensed under a Creative Commons Attribution 4.0 International License, which permits use, sharing, adaptation, distribution and reproduction in any medium or format, as long as you give appropriate credit to the original author(s) and the source, provide a link to the Creative Commons licence, and indicate if changes were made. The images or other third party material in this article are included in the article's Creative Commons licence, unless indicated otherwise in a credit line to the material. If material is not included in the article's Creative Commons licence and your intended use is not permitted by statutory regulation or exceeds the permitted use, you will need to obtain permission directly from the copyright holder. To view a copy of this licence, visit http://creativeco mmons.org/licenses/by/4.0/. The Creative Commons Public Domain Dedication waiver (http://creativecommons.org/publicdomain/ zero/1.0/) applies to the data made available in this article, unless otherwise stated in a credit line to the data. 
shortest possible time. The main aim of these 17 goals, which came into effect on January 1, 2016, is to transform the world and make it a better place for all" [3]. It is important to note that SDG2 in particular aims to "end hunger, achieve food security and improved nutrition and promote sustainable agriculture". The second part of the goal is to achieve food security. It is imperative to note that attainment of SDG2 will contribute principally to the achievement of the other goals of the 2030 agenda especially ending poverty; improving health; access to clean water and sanitation; decent work; and reduced inequality.

It is important to note that climate change, coupled with the soaring of prices, is threatening global food security thereby making governments all over the world to consider it as one of the topmost agenda [4]. According to FAO [5], food security is a situation that exists when all people, at all times, have physical, social and economic access to sufficient, safe and nutritious food that meets their dietary needs and food preferences for an active and healthy life. In this definition, there are four dimensions of food security: access, availability, use and sustainability. All these dimensions are important and form part of the SDG2.

The world over, food security has become a serious challenge and hence is receiving the attention of those who matter. According to Maxwell et al. [6], food security is central to policymakers and features in most of the current policy agenda than in the past. The level of food insecurity globally is a serious concern. The new ways of thinking, acting and monitoring to help achieve food security is not without challenges. It is estimated that the number of undernourished people in the world has increased from 804 million in 2016 to almost 821 million in 2017 suggesting that one out of every nine people in the world are undernourished [5]. The percentage of the total world (Africa) population who are severely food insecure has increased from 8.9\% (25.4\%) in 2016 to $10.2 \%$ (29.8\%) in 2017 [5]. This implies that about 770 million people are severely food insecure globally with Africa recording 256 million people. One of the greatest concern of the leaders of sub-Saharan African countries is how to feed their ever-increasing populations [7]. The question remains; what is happening to the plan of action aimed at ending food insecurity in the agenda 2030?

Irrespective of the gloomy picture painted above about the achievement of food security, Ghana has done significantly well. Among sub-Saharan African countries, the 2017 Global Food Security Index ranked Ghana as the third most food secured country after South Africa and Botswana [8]. From 2015 to 2017, the average percentage of Ghanaians who are severely food insecure is $7.9 \%$ and this value is far below the previous years and that of Africa [4]. The Northern Region of Ghana has the highest rate of stunted children with a prevalence of $33.0 \%$ [9]. As noted by [10], Ghana's food deficit is being solved through the importation of commercial food, and food aid. Postharvest loss is another principal cause of food insecurity in Ghana [10] and this can be reduced through improved storage facilities and market linkages. Climate change and variability have also been identified by [4] as drivers of food insecurity. The extremes of these conditions reduce agricultural productivity thereby reducing food availability, accessibility and utilization. It is gratifying to note that since 2008, the Government of Ghana (GoG) has put in place a 'National Fertilizer Subsidy Programme' [11] with the aim of providing subsidized fertilizer to farmers to help them improve agricultural productivity and household food security. In all, the policy priority of the Government of Ghana to achieving national food security has been national food self-sufficiency, i.e. the country being able to produce all its food needs [11].

To achieve food security, the rural-urban linkages should be strengthened through creating awareness of the general populace on SDGs [12]. Knowledge, they say is power, can ginger farmers on the need to work hard towards achieving global good of ending hunger in all forms. Meanwhile, to the best of our knowledge, there is no empirical research that establishes whether or not smallholder farmers' awareness of SDG2 improves their household food security status in the sub-Saharan African countries especially Ghana. There is no such study in Ghana and hence finding literature has been challenging. Therefore, the need for this research is non-negotiable. The overriding objective of the study is to estimate the effects of smallholder farmers' awareness of SDG2 on household food security in the Northern Region of Ghana.

\section{Methods \\ Study area}

The study was conducted in 2018 when the country was still having ten regions. Northern Region was the study area. Out of the then ten regions in Ghana, Northern Region was the largest in terms of land area. It has the lowest population density. The local government administration of the region is made up of one metropolis, eight municipalities and 19 districts. In terms of food insecurity, the Northern region is ranked third. Meanwhile, it is the region with the lowest population density in Ghana. The vast nature of the region means that SDG information delivery from the regional capital to the rural areas might be a challenge.

According to [13], the region has an estimated number of 491,700 households. Using 6\% margin of error, the [14] 
formula shown below gave a sample size of 278 for this study:

$$
\begin{aligned}
& n=\frac{N}{1+N e^{2}}, \\
& n=\frac{491,700}{1+491,700(0.06)^{2}}=277.62 \approx 278 .
\end{aligned}
$$

The study districts were selected using stratified sampling. With this, the districts were grouped into municipal assemblies and district assemblies. Out of the eight municipalities which form one stratum, Sagnarigu and West Mamprusi were selected using a stratified sampling technique. On the other hand, Mion and Gushegu districts were selected from the nineteen districts using a stratified sampling technique. This is to help us capture the holistic information on how awareness of SDGs affects household food security. Communities were selected using simple random sampling technique due to the homogeneity of the features within the communities. By using house numbers as the sampling frame, a systematic sampling technique was used to select households. This was made easy because the house numbers are arranged in order. A house where there are more than two households, only one household head who is available and willing to participate in the study was interviewed. A total sample size of 285 households was interviewed but 280 were used for this study. The five questionnaires that were not used had issues with missing data for some of the important variables. From Table 1, 52.8\% of the households included in this study are in municipalities with an equal percentage coming from Sagnarigu and West Mamprusi Municipalities. The frequency percentage of respondents from Gushegu and Mion Districts are $25.7 \%$ and $21.4 \%$, respectively. The municipalities recorded a higher number of respondents probably because they have a larger population.

\section{Conceptual framework}

Figure 1 shows the conceptual framework of the study. Conceptually, awareness of the SDG2 and whether the

Table 1 Percentage frequency distribution of households

\begin{tabular}{llcc}
\hline $\begin{array}{l}\text { Local } \\
\text { government } \\
\text { administration }\end{array}$ & $\begin{array}{l}\text { Districts/ } \\
\text { municipalities }\end{array}$ & Frequency & Percentage \\
\hline Municipalities & Sagnarigu & 74 & 26.4 \\
& West Mamprusi & 74 & 26.4 \\
Districts & Gushegu & 72 & 25.7 \\
& Mion & 60 & 21.4 \\
Total & & 280 & 100.00 \\
\hline
\end{tabular}

household is food secure or not are influenced by certain institutional and farmer-specific characteristics. Institutional factors such as access to information proxies as ownership of radio, television, access to the internet; distance to district and regional capitals, membership of a farmer-based organization and access to extension services influence farmers' awareness of the SDG2 and food security. Congruently, farmer-specific characteristics, which comprises the age of farmer, level of education, income level, farming experience, and household size affect farmers' awareness of the SDG2 and food security. Food security is also affected by dimensional factors such as the availability of food, accessibility of food, and the utilization of food.

Radically, individuals who have access to information or education may be more likely to be aware of national and global issues such the SDG2, which can influence their household food security. The access to information is influenced by ownership of a radio, television, computer/mobile phone or access to the internet. The proximity of an individual to information centres also affects his/her awareness of the SDG2. Individuals who live close to the districts and regional capitals where policies are often discussed may be more aware of SDG2 and that could influence their food security. According to [15], urban dwellers (who are closer to the district and regional capitals) are more food secure compared to rural dwellers. This shows that being closer to a district and regional capital has a positive influence on food security.

FBO membership and extension services, all things being equal are postulated to influence awareness of SDG2 and food security. Being a member of an FBO can expose farmers to information on SDG2 and food security issues. Additionally, extension officers through their interaction with farmers will provide information regarding the SDGs especially SDG2 and food security in general. Farmers in this category will be more likely to be food secured.

Awareness of SDG2 and food security are also likely to be influenced by some farmer- specific characteristics. For example, a farmers' educational level, age, income, farming experience, household size and farm size can one way or the other influence their awareness of SDG2 and food security level. Typically, older farmers are more mature and often have enhanced social networks compared to their younger counterparts. They are resultantly more privy to information which can influence their food security.

Additionally, personal adaptation factors such as diversification also affect food security. Farmers who diversify in either crops or animals are likely to improve their food security status as they will be able to withstand shocks from crop failure by relying on income from animals and vice versa. Also, farmers who participate in production 
training can increase their production levels using the new knowledge and technologies learnt. This has a direct impact on food security.

[16] reported that education positively influenced the food security status of households. This implies that households or individuals who are educated can access information on food security and SDG2 and hence are more informed and able to develop strategies to cope.

\section{Measurement of food security}

Prevalence of undernourishment is a long time UNdeveloped indicator for the measurement of food insecurity. To get a more reliable metric for global food security monitoring, Food Insecurity Experience Scale (FIES) was developed and accepted. FIES is a global food security measurement indicator that was built on the regional indicator developed and used by Latin America and the Caribbean more than a decade ago. It is food access dimension which measures food security at the individual level [4]. The FIES complements other four measures of food insecurity: Dietary diversity and food frequency (Food Consumption Score or Household Dietary Diversity Scale); Spending on food (Cost of Calorie); Consumption behaviours (Coping Strategies Index or Reduced Coping Strategies Index or Food Security Index); and Self-assessment measures (Self-assessed measure of food security). It is important to note that FIES is similar to Household Hunger Scale (HHS) used by [1] to investigate the determinants of food security in Savannah Accelerated Development Authority (SADA) Zone in Ghana. Any composite indexes that are used to measure food security should have good quality and feasible indicators [17]. As noted by Santeramo [17], some of the composite indexes used to measure food security are the Global Food Security Index (GFSI), the Global Hunger Index (GHI), and the Poverty and Hunger Index (PHI). Over the years several methods have been used to compute food security index and these methodologies have not been straightforward [17]. FIES uses different psychometric criteria and it is appropriate for assessing levels of food insecurity (i.e. from no food insecurity to severe food insecurity). However, HHS is different from

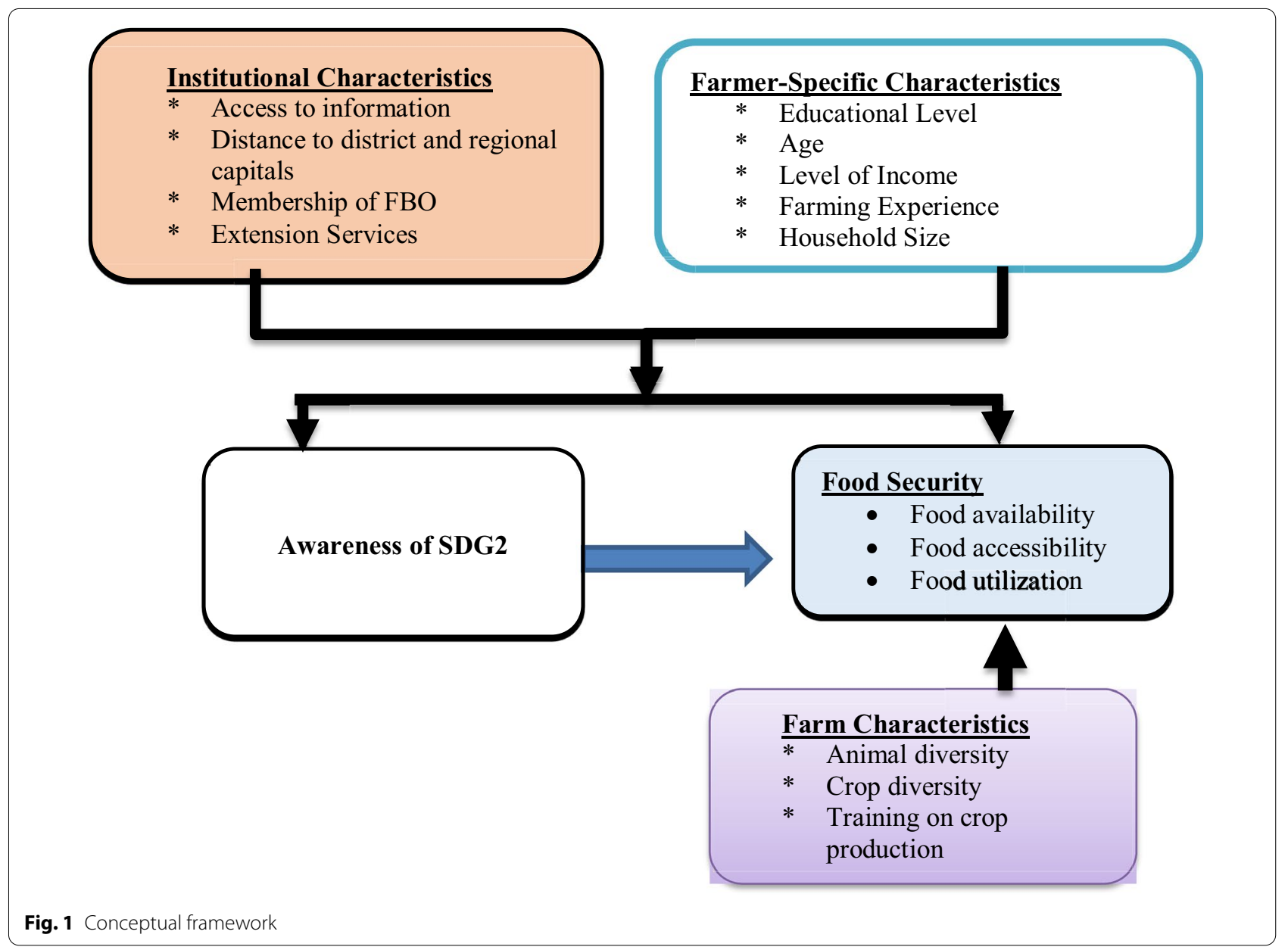


FIES and the other household food insecurity indicators as it assesses only the most severe experiences of food insecurity. The similarity between FIES and HHS is that both indicators can be used for cross-country and cultural comparison.

FIES is relatively new, easy to use and more appropriate for areas where there is evidence of food insecurity such as the Northern Region of Ghana. Though FIES is a perception-based indicator, the use of it in this study is appropriate since there is a high level of food insecurity in the Northern Region. As noted by [18], FIES has the strength of producing population-level estimates of food insecurity which can be compared across countries, cultures, and sub-populations. Brunellin et al. [19] opined that FIES is advantageous for the disaggregation of data by gender. It is important to note that this FIES is suitable for this study since the households are disaggregated into those who are aware of SDG2 and those who are unaware.

The eight-question Food Insecurity Experience Scale (FIES) is a new indicator for measurement of food security introduced by Food and Agriculture Organization (FAO), International Fund for Agricultural Development (IFAD), and United Nations International Children's Emergency Fund (UNICEF), World Food Programme (WFP) and World Health Organization (WHO) [4]. It estimates the proportion of the population who face serious constraints and ability to obtain sufficient food. With FIES, self-assessment of the behaviours and experiences of an individual and his/her household about increasing difficulties in accessing food due to resource constraints will be revealed. Smallholder farmers were asked "During the last 12 months, was there a time when, because of lack of money or other resources";

1. WORRIED: You were worried you would not have enough food to eat?

2. HEALTHY: You were unable to eat healthy and nutri-
The set of nine questions compose a scale that covers a range of severity of food insecurity. The total score for the affirmative responses is 9 whilst the total score for a negative response is 0 . A score of 0 represents food security. On the other hand, a score ranging from 1 to 9 implies food insecurity. If the scores are divided into three equal range, we obtain 1-3, 4-6 and 7-9 which represents mild food insecurity, moderate food insecurity and severe food insecurity, respectively [1].

\section{Endogenous switching regression treatment effects model with ordered outcome: impacts of awareness of SDG2 on food security}

The estimation of effects of smallholder farmers' awareness of SDG2 on food security level requires econometric model beyond binary or ordered choice models. The study requires the use of impact assessment or evaluation models, which use non-observational or non-experimental data. With such data, the problem one is likely to run into is sample selection bias [20]. One needs to deal with the problem of sample selection bias such that inherent characters do not provide the undue advantage of some households to be food secure irrespective of whether they are aware or not. Heckman sample correction, propensity score matching (PSM), endogenous switching regression model, generalized propensity score (GPS) matching in continuous treatment framework and treatment effects can be used to deal with the problem of sample selection [20-24].

The above-mentioned models are good for unordered outcome variables. Since the outcome variable (i.e. food insecurity level) is ordered, this study used endogenous switching regression treatment effects model with ordered outcome which has been developed by Gregory [25]. The assumption underlying this model is that the factors determining the ordered outcome differ between the treated and the untreated groups. Following Gregory [25], the selection equation, which represents the treatment model measuring the factors influencing the awareness of SDG2 is specified as:

$$
\text { AWARENESS_SDG } 2_{i}=\left\{\begin{array}{ll}
1 & \text { if AWARENESS_SDG } 2 *=X_{j i} \beta_{j}+\varepsilon_{i}>0 \\
0 & \text { if AWARENESS_SDG } 2_{i}^{*}=X_{j i} \beta_{j}+\varepsilon_{i} \leq 0
\end{array},\right.
$$

tious food?

3. FEWFOODS: You ate only a few kinds of foods?

4. DISLIKEFOOD: You ate food you do not like?

5. SKIPPED: You had to skip a meal?

6. ATELESS: You ate less than you thought you should?

7. RANOUT: Your household ran out of food?

8. HUNGRY: You were hungry but did not eat?

9. WHOLEDAY: You went without eating for a whole day? where AWARENESS_SDG $2_{i}=$ Awareness of SDG2 ( 1 if the household head is aware and 0 otherwise); $X_{j i}=$ jth explanatory variable and $\varepsilon_{i}=$ error term for ith household.

As typical of an endogenous switching regression model, the second equation explaining the factors influencing food insecurity levels is segregated for farmers who are aware and those who are not aware of SDG2. 
Therefore, following the originator of the model, Gregory [25], the drivers of food insecurity level (FIL) for the farmers who are not aware and those who are aware of SDG2 are specified in Eqs. 3 and 4, respectively:

$$
\begin{aligned}
& F I L_{0 i}=\left\{\begin{array}{c}
0 \text { if }-\infty<Z_{0 i} \beta_{0}+\ell_{0 i} \leq \mu_{00} \\
1 \quad \text { if } \mu_{00}<Z_{0 i} \beta_{0}+\ell_{0 i} \leq \mu_{01} \\
\ldots \\
3 \quad \text { if } \mu_{03}<Z_{0 i} \beta_{0}+\ell_{0 i} \leq \infty
\end{array}\right. \\
& F I L_{1 i}=\left\{\begin{array}{l}
0 \text { if }-\infty<Z_{1 i} \beta_{1}+\ell_{1 i} \leq \mu_{10} \\
1 \text { if } \mu_{10}<Z_{1 i} \beta_{1}+\ell_{1 i} \leq \mu_{11} \\
\cdots \\
3 \quad \text { if } \mu_{13}<Z_{1 i} \beta_{1}+\ell_{1 i} \leq \infty
\end{array},\right. \\
& \operatorname{ATE}_{k}^{s}=\frac{1}{N} \frac{1}{S} \sum_{i=1}^{N} \sum_{s=1}^{S}\left[\Phi\left\{\mu_{1 k}-\left(Z_{1 i} \beta_{1}+\gamma_{1} \tau_{i s}\right)\right\}-\Phi\left\{\mu_{1 k-1}-\left(Z_{1 i} \beta_{1}+\gamma_{1} \tau_{i s}\right)\right\}\right] \\
& -\left[\Phi\left\{\mu_{0 k}-\left(Z_{0 i} \beta_{0}+\gamma_{0} \tau_{i s}\right)\right\}\right]-\Phi\left\{\mu_{0 k-1}-\left(Z_{0 i} \beta_{0}+\gamma_{0} \tau_{i s}\right)\right\} .
\end{aligned}
$$

\section{Marginal effects: average treatment effect (ATE)}

Treatment effects measure the magnitude of the effects of treatment on the outcome. Average treatment effect in this study measures the magnitude of the effect of awareness of SDG2 on food insecurity level for randomly selected household heads from the study area as against the effect of awareness on food insecurity if they had not been aware. Following Gregory [25], and given that $S$ is the simulation draws, $\gamma$ is the loading factor, $\Phi$ is the standard normal cumulative distribution, $k=1,2$, ..., $K$ and $K=J+1$ and $J$ is the number of choices ( 4 as in this study), the ATT for endogenous switching regression treatment effects model with ordered outcome is speci- where $Z_{k i}=$ kth explanatory variable affecting the ith household FIL; 0, 1, 2, 3 represents the food insecurity levels (FIL) with 0 being food secure, 1 mildly food insecure, 2 moderately food insecure and 3 severely food insecure.

In this study, we validate the hypothesis that smallholder farmers who are aware of SDG2 are more food secure than their counterparts who are not aware of SDG2. Endogenous switching regression treatment effects model with ordered outcome can account for this endogeneity which when present may lead to inconsistent estimates if not dealt with. This is because some farmers may be aware of SDG2 because of certain information they are privy to or characteristics they have. If the endogeneity of the awareness is not taken care off, the estimated effect of the awareness on food insecurity level might be over or under.

As suggested by Gregory [25], endogenous switching regression treatment effects model with ordered outcome can be estimated using maximum likelihood where the error terms between the outcome treatment $(\varepsilon 1)$ and the outcome $(\ell)$ are assumed to follow a bivariate normal distribution. However, this assumption can yield inconsistent estimates if indeed it is not entirely the case. To overcome this, we used Halton-based sequences [26] drawn from the distributions of latent-factors (factors which are unobserved but affect both awareness and food insecurity levels). As suggested by Deb and Trivedi [27] and Train [28], the advantages of Halton sequences are even covering of the domain of distribution, reduction of the variances and reduction of the computational time.
Note also that $S$ represents switching regression model, $N$ is the number of observations $\mu_{0}=-\infty, \mu_{0}=\infty$.

\section{Results and discussion}

This section presents and discusses the results of the research. A test of the differences between socioeconomics variables of household heads who are aware and those who are not aware of SDG2 is first presented and discussed. This is followed by the frequency distribution of household food security levels before factors influencing awareness of SDG2. The section ends with the impact of awareness of SDG2 on household food security.

\section{Differences between socioeconomics variables}

Table 2 shows a test of the socioeconomic factors for the two groups of the respondents (those who are aware and those not aware). The results show that food insecurity experience score (FIES) of households is significantly lower for household heads who are aware of SDG2 than those who are unaware. Farmer characteristics which showed significant differences between the two groups of respondents are age, sex, education, opinion leadership, FBO membership, off-farm activities and farming experience.

Also, apart from training on crop production and ownership of TV, all the factors measuring access to information on SDG2 differ between the group who are aware and those who are not aware of. The significant information access variables are distance to the district capital, distance to the regional capital, training on animal production, ownership of mobile phone and ownership of 
Table 2 Description, measurement and statistics of explanatory variables

\begin{tabular}{|c|c|c|c|c|}
\hline \multirow[t]{2}{*}{ Description (variable) } & \multirow[t]{2}{*}{ Measurement } & \multicolumn{2}{|l|}{ Mean $^{a}$} & \multirow[t]{2}{*}{$t$-test } \\
\hline & & Aware (165) & Not aware (120) & \\
\hline Food Insecurity Experience Score (FIES) & $\begin{array}{l}0=\text { food secure; } 1-3=\text { mild food insecurity; } \\
4-6=\text { moderate food insecurity; } 7-9=\text { severe food } \\
\text { insecurity }\end{array}$ & 2.55 & 3.98 & $4.26^{* * *}$ \\
\hline \multicolumn{5}{|l|}{ Farmer characteristics } \\
\hline Age & Years & 46.30 & 43.05 & $2.10^{* *}$ \\
\hline Sex & $1=$ male $0=$ female & 0.93 & 0.68 & $5.48^{* * *}$ \\
\hline Household size & Number of people in a household & 14.04 & 14.38 & 0.31 \\
\hline Education of household head & Years of education & 2.46 & 1.75 & $1.38^{*}$ \\
\hline Opinion leader & $1=$ opinion leader, $0=$ otherwise & 0.37 & 0.29 & $1.38^{*}$ \\
\hline FBO membership & $1=$ member, $0=$ otherwise & 0.58 & 0.19 & $7.27^{* * *}$ \\
\hline Engagement in off-farm & $1=$ engaged in off-farm activity, $0=$ otherwise & 0.68 & 0.58 & $1.64^{*}$ \\
\hline \multicolumn{5}{|l|}{ Information access variable } \\
\hline Distance to district capital & Kilometres (km) & 5.07 & 7.08 & $3.78^{* * *}$ \\
\hline Distance to regional capital & Kilometres (km) & 74.16 & 90.62 & $3.06^{* * *}$ \\
\hline Training on animal production & $1=$ trained, $0=$ not trained & 0.15 & 0.08 & $1.81^{* *}$ \\
\hline Training on crop production & $1=$ trained, $0=$ not trained & 0.22 & 0.21 & 0.32 \\
\hline Ownership of TV & $1=$ own TV, $0=$ do not own TV & 0.39 & 0.35 & 0.65 \\
\hline Ownership of phone & $1=$ own phone, $0=$ do not own phone & 0.94 & 0.74 & $4.47^{* * *}$ \\
\hline Ownership of radio & $1=$ own radio, $0=$ do not own radio & 0.82 & 0.63 & $3.73^{* * *}$ \\
\hline E-extension contact & $1=$ yes, $0=$ otherwise & 0.51 & 0.18 & $6.18^{* * *}$ \\
\hline \multicolumn{5}{|l|}{ Wealth and welfare variables } \\
\hline Animal diversity & Numbers of species of animal reared & 3.04 & 1.83 & 6.75 \\
\hline Crop diversity & Numbers of crops cultivated & 3.01 & 2.42 & $3.50^{* * *}$ \\
\hline Farm size & Acres & 11.34 & 7.10 & $4.42^{* * *}$ \\
\hline \multicolumn{5}{|l|}{ Institutional and policy variables } \\
\hline Number of contacts with agricultural extension & Numbers of contacts per year & 1.57 & 0.94 & $2.80^{* * *}$ \\
\hline Credit access & $1=$ access to credit, $0=$ otherwise & 0.48 & 0.23 & $4.75^{* * *}$ \\
\hline Beneficiary of any NGO interventions & $1=$ yes, $0=$ otherwise & 0.48 & 0.19 & $4.42^{* * *}$ \\
\hline Access to electronic extension & $1=$ yes, $0=$ otherwise & 0.51 & 0.18 & $6.18^{* * *}$ \\
\hline
\end{tabular}

a For dummy variables, the values under the "mean" column describe the proportion of the respondents coded 1

radio. For wealth variables, crop diversity and farm size showed a significant difference between the two groups.

All the institutional variables showed significant differences between the two groups. Farmers who are aware of SDG2 had approximately 2 number of contacts with agricultural extension agents as compared with their counterparts who received approximately contacts a year. Whilst $48 \%$ of the household heads who are aware of SDG2 had access to credit, only $23 \%$ of those who are unaware had access to credit. Similarly, there is a significant difference between the proportion of household heads who are beneficiaries of any NGO interventions and have access to electronic extension for the two groups of respondents. The e-extension is accessing agricultural extension information through radio, TV or any other digital platform such as mobile phones.

\section{Frequency distribution of food security status of households}

Figure 2 depicts the percentage frequency distribution of food security status of households. From the figure, $24.2 \%$ of the households are food secured. These households had FIES value of 0 . Whilst the highest proportion $(34.7 \%)$ of households are suffering from mild food insecurity, the least proportion (14.7\%) are suffering from severe food insecurity. The pattern of distribution is similar to that of [1].

Food security is the ideal situation but mild food insecurity is not too bad. Out of 280 households, 34.7\% who are mild food insecure suggest that members are worried about their ability to obtain food. With moderate food insecurity, households compromise quality and variety of food they eat and reduce the quantity of food they eat or even skip meals. $14.7 \%$ of households 


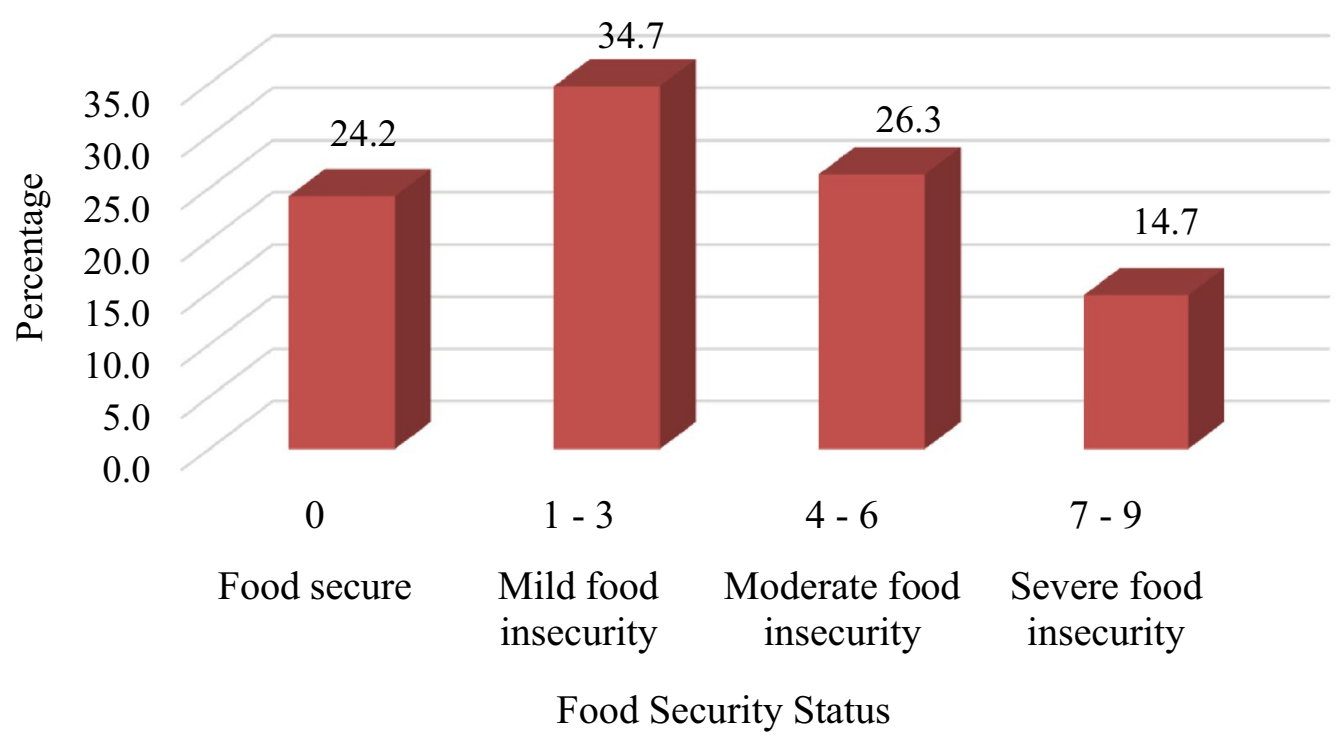

Fig. 2 Percentage frequency distribution of food security status of households

suffering from severe food insecurity means that their household members experienced hunger. The pattern of food security conforms to the observation by [10] that,
Ghana is generally food secure, but pockets of food insecurity prevalent in all regions are due to acutely limited resources and limited alternative livelihood supports for

Table 3 Determinants of awareness of SDG2 and household food insecurity levels

\begin{tabular}{|c|c|c|c|c|c|c|}
\hline \multirow[t]{2}{*}{ Variables } & \multicolumn{2}{|c|}{ Awareness of SDG2 } & \multicolumn{2}{|c|}{ Non-aware of SDG2 } & \multicolumn{2}{|l|}{ Aware of SDG2 } \\
\hline & Coef & Std. Err & Coef & Std. Err & Coef & Std. Err \\
\hline Household size & -0.0064 & 0.0128 & 0.0100 & 0.0176 & -0.0109 & 0.0323 \\
\hline Education of household head & $0.0630^{*}$ & 0.0354 & -0.0612 & 0.0494 & -0.0963 & 0.0657 \\
\hline Distance to regional capital & $-0.0067^{* *}$ & 0.0029 & 0.0028 & 0.0032 & 0.0115 & 0.0088 \\
\hline Age & $0.0222^{*}$ & 0.0114 & 0.0051 & 0.0128 & $-0.0500^{* *}$ & 0.0200 \\
\hline Engagement in off-farm & -0.0071 & 0.2871 & 0.0006 & 0.2974 & -0.9135 & 0.6847 \\
\hline Opinion leader & 0.3818 & 0.3103 & $-0.6164^{*}$ & 0.3545 & -0.6706 & 0.7919 \\
\hline Face-to-face extension contacts & -0.0096 & 0.0758 & $-0.1545^{*}$ & 0.0873 & $-0.4886^{*}$ & 0.2554 \\
\hline Access to e-extension & $0.7128^{* *}$ & 0.3606 & -0.1330 & 0.4340 & $-2.4033^{* *}$ & 0.9537 \\
\hline FBO membership & $0.6622^{*}$ & 0.3497 & -0.5434 & 0.4210 & -0.4667 & 1.0196 \\
\hline Training on crop production & -0.4046 & 0.3612 & $-1.3472^{* * *}$ & 0.4195 & 1.3369 & 0.9665 \\
\hline Farm size & $0.0649^{* * *}$ & 0.0228 & -0.0395 & 0.0343 & -0.0438 & 0.0502 \\
\hline Animal diversity & & & $0.2082^{*}$ & 0.1127 & $-0.7921^{* * *}$ & 0.2625 \\
\hline Crop diversity & & & -0.0290 & 0.1152 & 0.1535 & 0.2292 \\
\hline Ownership of radio & $0.0218^{*}$ & 0.0127 & & & & \\
\hline _cons & $-1.2905^{*}$ & 0.6625 & & & & \\
\hline /cut_01 & 0.1948 & 0.7777 & \multicolumn{4}{|c|}{ Wald $\mathrm{Chi}^{2}(12)=46.47^{* * *}$} \\
\hline /cut_02 & $1.6534^{* *}$ & 0.7860 & \multicolumn{4}{|c|}{ Log-likelihood $=-47,061.85$} \\
\hline /cut_03 & 10.0683 & $83,731.260$ & \multicolumn{4}{|c|}{ Prob $>\mathrm{Chi}^{2}=0.0000$} \\
\hline /cut_11 & -7.0227 & & \multirow{2}{*}{\multicolumn{4}{|c|}{$\begin{array}{l}\text { Test of independent treatment and outcome, treated } \\
\text { group }=12.05(\text { Prob }=0.000)\end{array}$}} \\
\hline /cut_12 & $-4.3106^{* * *}$ & 0.7230 & & & & \\
\hline /cut_13 & 9.9975 & $69,158.610$ & \multicolumn{4}{|c|}{ Test of distinct regimes $=7.24($ Prob $=0.01)$} \\
\hline /lambda0 & -0.6456 & & & & & \\
\hline /lambda1 & $-2.8698^{* * *}$ & 0.8266 & & & & \\
\hline
\end{tabular}


most people to meet their dietary needs. Similarly, in Northern Ghana, pockets of mild food insecurity, moderate food insecurity and severe food insecurity exist due to poverty and limited access to alternative livelihoods activities.

\section{Determinants and impact of awareness of SDG2 on household food security \\ Diagnostic test for the appropriateness of the model}

Table 3 shows the estimation results of treatment effects model with ordered using switchoprobitsim estimator. From the table, the Wald Chi-square test which measures the fitness of the model is statistically significant at $1 \%$. The significance of the Wald Chi-square test implies that the data fits well for the model. The distribution of the household food insecurity level differs among the household heads who are aware and those who are not aware of SDG2. This is premised on the statistical significance of the test of independence of treatment and outcome. The test of distinct regimes is statistically significant at $5 \%$ implying that factors explaining the variations in the household food insecurity levels of household heads who are aware and those who are not aware of SDG2 differ. This, therefore, justifies the use of switchoprobitsim proposed and popularized by Gregory [25] for the analysis.

The log-likelihood ratio test value of 47,061.85 is statistically significant at $1 \%$, implying that the alternate hypothesis of strong correlation between the error terms of selection (awareness) and the food insecurity level models is valid. Therefore, stochastic factors not included in the awareness and food insecurity level models are related. Also, in estimating the treatment effect model with ordered outcome using switchoprobitsim estimator, the problem of endogeneity need to be overcome by including at least one instrument which affects awareness but not food insecurity level. To get an appropriate instrument, a falsification test suggested by Di Falco [29] was performed and ownership of radio was settled on. This was based on the fact that the instrument (ownership of radio) was (i) correlated with the endogenous variable thus awareness of SDG2 and (ii) uncorrelated with the unobserved variables (error terms) of the outcome equations in both regimes.

\section{Determinants of awareness of SDG2}

The second and third columns in Table 3 present the coefficients and the standard errors, respectively, of the selection model which estimates the determinants of awareness of SDG2. Years of education of household head is statistically significant at $10 \%$. The positive direction of effects meets the a priori expectation. This implies that household heads who have spent many years in education have higher probabilities of being aware of SDG2. Education plays a significant role in farmers' access to information and hence the awareness of SDG2. Age is statistically significant at $1 \%$. The coefficient value of 0.0222 of age implies that if the age of the household head age increases by 1 year, the probability of awareness of SDG2 will increase by $2.22 \%$. This is because information access increases with age.

The distance from the regional capital is statistically significant at $5 \%$ and meets the a priori expectation. The negative signs of the coefficients imply that households who are closer to regional capital have a higher probability of being aware of SDG2. The direction of this effect was expected because regional capital is the town that is relatively developed with radio and well-educated and informed people. Communities closer to this town receive the spill-over effects of the information on SDG2.

E-extension provides information to farmers. Through, e-extension, some of the farmers can get information about SDG2. This is the reason why farmers who access agricultural information from extension officers through electronic medium have $71.3 \%$ probability of being aware of SDG2 than their counterparts. This explains why use of e-extension is statistically significant at $5 \%$. It is not surprising seeing that households with electronic agricultural extension contacts have a higher probability of being aware of SDG2. Lastly, the ability of e-extension in reducing food insecurity. The significant effect of e-extension supported the explanation by MoFA [30] that the promotion of e-agriculture can support operations of the agricultural sector, and strengthen the convergence of agricultural information to improve knowledge sharing and public access to information. FBO membership increases the probability of households' awareness of SDG2 since the coefficient is positive and significant at $10 \%$. The probability of awareness of SDG2 of household heads who are members of FBOs is 0.66 greater than those who are not aware. FBOs provide information for members and this may include information on SDG2.

Farm size is highly significant at $1 \%$. As the farm size of a farmer increases, the farmer moves from subsistent level towards commercialization level. Farmers who are commercialized are usually highly educated and wellendowed people in the community. Such farmers have more knowledge about the happenings in the world. Therefore, if the farm size of a farmer increases by 1 acre, the probability of awareness of SDG2 will increase by $6.5 \%$.

Ownership of radio is statistically significant at $10 \%$. The direction of the effect of ownership of radio meets the expected hypotheses. Ownership of radio is a key determinant of awareness of SDG2. Households who have access to radio have a higher probability of being aware of SDG2. The radio transmits information and 
most of the information broadcast is in local languages which makes it easy for farmers to understand. Also, some radio programmes broadcast information that is related to agricultural production and sustainable development.

\section{Drivers of food security}

There are differences between factors determining food security for farmers who are aware and those who are not aware of SDG2 due to heterogeneity among the two groups. Columns 4 and 5 and columns 6 and 7 in Table 3 show the models for drivers of food insecurity of unaware and aware household heads.

Factors explaining food insecurity of households who are not aware of SDG2 Factors which explain the variations in the levels of food security for farmers who are not aware of SDG2 are whether one is opinion leader or not, the number of face-to-face extension contacts, training on crop production, diversity of animals reared. This is based on the fact all these factors are statistically significant at $10 \%$ except training on crop production which highly statistically significant at $1 \%$ in the non-awareness of SDG2 model. Whilst the influence of all these significant factors meets the expected direction of effects, animal diversity is at variance with the economic theory. Opinion leaders are usually well-endowed farmers who command respect in the community. As shown in Table 3, household heads who are opinion leaders in the community have $61.6 \%$ food insecurity level more than those who are not. It is clear from Table 3 that farmers who receive agriculture extension information through face-to-face means have $15.5 \%$ food insecurity level more than their counterparts. Agricultural extension officers are supposed to educate farmers on improved agricultural practices. With this, farmers are expected to obtain higher yield and become food secure. Training on crop production is critical to farmers. Farmers who have been trained in crop production is are more food secure than those who have not received any training. Training on crop production capacitates farmers on all the necessary skills needed to increase agricultural productivity and have more food for the households. It is along with this understanding that Feder et al. [31] noted that training programmes are key to capacitating farmers on knowledge about emerging agricultural technological innovations.

Factors explaining food insecurity of households who are aware of SDG2 On the other hand, the level of food security of households who are aware of SDG2 is determined by age, number of face-to-face extension contacts, use of electronic medium to access agricultural information, and animal diversity. This is because the directions of effects of all these variables meet the a priori expectation. Whilst age and use of electronic agricultural extension are statistically significant at $5 \%$ each, crop diversity is $1 \%$ statistically significant. Number of face-to-face agricultural extension contacts is statistically significant at $1 \%$. An increase in the age of a household head by 1 year leads to a decrease in food insecurity level by $5 \%$. This implies that the food security of a household increases with increasing age. Older household heads are expected to have more resources and different sources of income which are expected to translate into more food for their family as compared to younger household heads.

Also, farmers who access agricultural extension information through face-to-face have $48.9 \%$ food insecurity level less than their counterparts. Agricultural extension officers are agents of change who through their interaction with farmers sometimes tell them how they can marshal resources to face the lean season and be more food secure. Similarly, use of e-extension tends to decrease food insecurity levels. As alluded above, agricultural extension information irrespective of its sources is expected to help farmers adopt improved agricultural technologies, increase agricultural productivity and have more food for the family and hence become more food secure. In Ghana, agricultural extension agents are expected to train farm households on agricultural production just as what is happening in South Africa [32]. As opined by Mutea [33], agricultural extension is a form of social-political relation with the local agricultural authority which expedites easy access to information on technologies and hence likely to improve food security through agricultural productivity improvement.

It is not surprising to see that as one rears different types of animals, one becomes more food secure. This is because animals are assets and can be sold to purchase food for the household. This finding is line with the assertion by Gebrehiwot [34] that households engage in livestock rearing so that they can sell them for money in the time of dire need for food and other household emergency requirements. Ngema et al. [32] confirmed this by noting that livestock farming is a livelihood strategy. Also, animals can be slaughtered and the meat eaten as food.

The non-significance of education in both models confirms the finding of [35]. They explained that educated households may not be using their knowledge to achieve food security. Farm size is statistically insignificant. This is at variance with the work of [1] that yield decreases the probability of experiencing severe food security. They indicated that this has a key policy implication for government and development partners who are interested in providing interventions to smallholder farmers and fighting food security. 
Table 4 ATT and ATE measuring impacts of awareness of SDG2 on food security levels

\begin{tabular}{llccc}
\hline Levels of food insecurity & Food security status & Obs & Mean & Std. Dev \\
\hline 0 & Food secure & 47 & 0.007 & 0.003 \\
1 & Mild food insecurity & 65 & 0.114 & 0.115 \\
2 & Moderate food insecurity & 33 & 0.113 & 0.112 \\
3 & Severe food insecurity & 20 & 0.039 & -0.011 \\
Average treatment effect on the treated (ATT) & & 165 & -0.081 & 0.143 \\
0 & Food secure & 69 & -0.223 & 0.129 \\
1 & Mild food insecurity & 99 & -0.260 & 0.316 \\
2 & Moderate food insecurity & 75 & -0.128 & 0.237 \\
3 & Severe food insecurity & 42 & 285 & 0.302 \\
Average treatment effect (ATE) & & & & \\
\hline
\end{tabular}

\section{Impacts of awareness of SDG2 on food security}

Table 4 shows that awareness of SDG2 has significant effects on household FIES. The value of ATT is 0.039 suggesting that if a farmer who is aware of SDG2 shifts from being aware to becoming unaware, the food insecurity level of his or her household is expected to increase by 0.039 . This implies that if a household moves from awareness of SDG2 to non-awareness, his or her household is expected to be less food secure.

The ATE measures the difference in average food insecurity levels of households whose heads are aware and not aware of SDG2. The negative sign of the ATE shows the direction of the impact. As shown in Table 4, the negative sign of ATE value implies that household who are aware of SDG2 have lower levels of food insecurity. Therefore, household heads who are aware of SDG2 have $12.8 \%$ lower food insecurity level than those who are not aware. In other words, household heads who are aware of SDG2 are $12.8 \%$ more food secure than their counterparts. Households at different food security status have varying effects of awareness on food security status. The effects of awareness of SDGs on food insecurity levels is highest for households who are severely food insecure followed by those who are moderately food insecure, mildly food insecure and food secure in that order. Therefore, a household whose head is aware of SDG2 is more food secure compared to a household whose head is unaware. As noted by [28], knowledge sharing and communication are cardinal factors that improve food security. Furthermore, the significant impact of awareness of SDG2 on food security is in line with [36] that information farmers have helped them to adopt technologies with the ultimate aim of getting higher productivity. This implies that knowledge on SDG2 is critical to improving food security of rural folks and hence information on goal 2 should be widely disseminated and promoted. It is worth noting that this impact resonates with the food security learning framework which seeks to link the investment in other sectors such as SDGs. The findings of our study confirmed the food security learning framework which according to FAO [37] recognizes the information as critical to the achievement of food security.

\section{Conclusion}

Sustainable development is a critical issue for world leaders. This led to the development and promotion of 17 sustainable development goals by the United Nations. Among them is the SDG2 which is "end hunger, achieve food security and improved nutrition and promote sustainable agriculture". This study investigated the factors influencing smallholder farmers' awareness of SDG2, drivers of household food insecurity level as well as the impacts of the awareness on food insecurity using endogenous switching regression treatment effects model with ordered outcome.

From the study, household heads who are aware of SDG2 are more food secured than their counterparts. The study found that awareness of SDG2 is determined by age, the distance of households to the regional capital, members of farmer-based organizations, access to e-extension, education, and ownership of radio. Food security is determined by age, whether one is opinion leader or not, face-to-face extension contact, access to e-extension, training on crop production and diversification in livestock rearing. Community information centres should be established where smallholder farmers can assembly to listen to radio programmes related to agricultural production and sustainable development goals. Also, governments and duty-bearers should make it easy for every household to own a radio set. Government and development partners should institute a radio programme on sustainable development goals. It is therefore prudent for stakeholders promoting and championing SDGs to educate farmers on the sustainable 
Development Goal 2 as their awareness of the goal is critical to achieving food security. Duty-bearers such as government, NGOs and opinion leaders should endeavour to make conscious efforts to educate smallholder farmers on SDGs especially the goal 2.

\section{Abbreviations}

FAO: Food and Agriculture Organization; FIES: Food Insecurity Experience Scale; IFAD: International Fund for Agricultural Development; GFSI: Global Food Security Index; GHI: Global Hunger Index; GoG: Government of Ghana; GSS: Ghana Statistical Service; PHI: Poverty and Hunger Index; SDGs: Sustainable Development Goals; UNICEF: United Nations International Children's Emergency Fund; WFP: World Food Programme; WHO: World Health Organization.

\section{Acknowledgements}

We acknowledge in particular the respondents for providing us with all the necessary information. Also, we appreciate the hurdle that the enumerators went through to successfully collect the data.

\section{Authors' contributions}

FNM designed the study and wrote the manuscript. EM and NS developed the study tools, provided in-depth review and edited the manuscript. All authors read and approved the final manuscript.

\section{Funding}

The data collection was funded by the African Development Bank (AfDB) through the Japan Trust Fund as allocated by the Ministry of Finance, Japan.

\section{Availability of data and materials}

The data are available and will be provided upon official request.

\section{Ethics approval and consent to participate}

Not applicable.

\section{Consent for publication}

All authors provided consent for the publication of this paper.

\section{Competing interests}

All authors state no competing interests.

\section{Author details}

${ }^{1}$ Department of Agricultural and Resource Economics, Faculty of Agribusiness and Applied Economics, University for Development Studies, Tamale, Ghana. ${ }^{2}$ Department of Communication and Innovation Technology, Faculty of Communication and Cultural Studies, University for Development Studies, Tamale, Ghana. ${ }^{3}$ Department of Agricultural Extension, Rural Development and Gender Studies, Faculty of Agribusiness and Applied Economics, University for Development Studies, Tamale, Ghana.

Received: 1 April 2020 Accepted: 16 December 2020

Published online: 18 March 2021

\section{References}

1. Nkegbe PK, Abu BM, Issahaku H. Food security in the Savannah accelerated development Authority Zone of Ghana: an ordered probit with household hunger scale approach. Agric Food Secur. 2017;6(35):1-11.

2. Mensah J, Casadevall SR. Sustainable development: meaning, history, principles, pillars, and implications for human action: literature review. Cogent Soc Sci. 2019;5(1):1-21.

3. Ghana Statistical Service (GSS). Data Production for SDG indicators in Ghana, Accra. 2017.

4. Leroy JL, Ruel M, Frongillo EA, Harris J, Ballard TJ. Measuring the food access dimension of food security: a critical review and mapping of indicators. Food Nutr Bull. 2015;36(2):167-95.

5. Food and Agriculture Organization (FAO), International Fund for Agricultural Development (IFAD), and United Nations International Children's
Emergency Fund (UNICEF), World Food Programme (WFP) and World Health Organization (WHO). The State of Food Security and Nutrition in the World 2018. Building climate resilience for food security and nutrition. Rome, FAO. 2018; Licence: CC BY-NC-SA 3.0 IGO.

6. Maxwell D, Coates J, Vaitla B. How do different indicators of household food security compare? Empirical evidence from Tigray. Medford: Feinstein International Center, Tufts University; 2013.

7. Owusu V, Abdulai A, Abdul-Rahman S. Non-farm work and food security among farm households in Northern Ghana. Food Policy. 2011;2011(36):108-18.

8. The Economist Intelligent Unit. Global Food Security Index 2018 Building resilience in the face of rising food-security risks, 2018.

9. Ghana Statistical Service (GSS), G. H. S. G., and ICF International, (2015). Ghana Demographic and Health Survey 2014.

10. Darfour B, Rosentrater KA. Agriculture and Food Security in Ghana. A Paper presented at Agricultural and Biosystems Engineering Conference of American Society of Agricultural and Biological Engineers (ASABE) at Orlando, Florida, July 17-20, 2016. Paper No. 162460507, pages 1-11

11. Ministry of Food and Agriculture (MoFA). Planting for food and jobs concept - a program to stimulate rapid growth of the Ghanaian agricultural sector. Accra: Ministry of Food and Agriculture; 2017.

12. International Food Policy Research Institute (IPRI). Global Food Policy Report. Washington: International Food Policy Research Institute; 2017. p. 2017.

13. GSS. Ghana Living Standards Survey Round 6 (GLSS 6), Main Report, Ghana Statistical Service, Accra, 2014.

14. Yamane T. Statistics, an introductory analysis. 2nd ed. New York: Harper and Row; 1967.

15. Sisha TA. Household level food insecurity assessment: evidence from panel data Ethio. Scientific African. 2020;7:e00262.

16. Ngem PZ, Sibanda M, Musemwa L. Household food security status and its determinants in Maphumulo local municipality, South Africa. Sustainability. 2018;10(9):3307.

17. Santeramo FG. On the composite indicators for food security: decisions matter! Food Rev Int. 2015;31(1):63-73.

18. INDDEX Project, Data4Diets: Building Blocks for Diet-related Food Security Analysis., 2018; Tufts University, Boston, MA. https://inddex.nutrition.tufts .edu/data4diets. Accessed 6 July 2020.

19. Brunellin C, Viviani S, Exploring gender-based disparities with the FAO Food Insecurity Experience Scale, Statistics Division, Food and Agriculture Organization of the United Nations (FAO), Italy, 2014

20. Heckman J. Sample selection bias as a specification error. Econometrica. 1967;47(1):153-61.

21. Shiferaw B, Kassie M, Jaleta M, Yirga C. Adoption of improved wheat varieties and impacts on household food security in Ethiopia. Food Policy. 2014;2014(44):272-84.

22. Hirano K, Imbens GW. The propensity score with continuous treatments. Applied Bayesian modeling and causal inference from incomplete-data perspectives, 2004; 73-84

23. Wooldridge JM. Instrumental estimation of the average treatment effect in the correlated random coefficient model. Michigan: Department of Economics, Michigan State University, Michigan; 2005.

24. Asfaw S, Di Battistab F, Lipper L. Agricultural Technology Adoption under Climate Change in the Sahel: Micro-evidence from Niger, J Afr Econ, 2016; 25:1-33.

25. Gregory CA. Estimating treatment effects for ordered outcomes using maximum simulated likelihood. Stata J. 2015;15(3):756-74.

26. Drukker DM, Gates R. Generating Halton sequences using Mata. Stata J. 2006;6:214-28.

27. Deb P, Trivedi PK. Maximum simulated likelihood estimation of a negative binomial regression model with multinomial endogenous treatment. Stata J. 2006;6:246-55.

28. Train KE. Discrete choice methods with simulation. 2nd ed. Cambridge: Cambridge University Press; 2009.

29. Di Falco S. Adaptation to climate change in Sub-Saharan agriculture: assessing the evidence and rethinking the drivers. Eur Rev Agric Econ. 2014;41(3):405-30.

30. Ministry of Food and Agriculture (MoFA). Investing for Food and Jobs (IFJ): An Agenda for Transforming Ghana's Agriculture (2018-2021), Ministry of Food and Agriculture, 2018; Accra 
31. Feder $G$, Birner R, Anderson JR. The private sector's role in agricultural extension systems: potential and limitations. J Agribus Dev Emerg Econ. 2011;1(1):31-54.

32. Ngema PZ, Sibanda M, Musemwa L. Household food security status and its determinants in Maphumulo Local Municipality South Africa. Sustainability. 2018;10(3307):1-23.

33. Mutea E, Rist S, Jocobi J. Applying the theory of access to food security among smallholder family farmers around North-West Mount Kenya. Sustainability. 2020;12(1751):1-14.

34. T Gebrehiwot 2008 Rural Food Security in Tigray, Ethiopia: Policy Impact Evaluation Enschede, The Netherlands International Institute for GeoInformation Science and Earth Observation
35. Babatunde RO, Qaim M. Impact of off-farm income on food security and nutrition in Nigeria. Food Policy. 2010;2010(35):303-11.

36. Meijer SS, Catacutan D, Ajayi OC, Sileshi GW, Nieuwenhuis M. The role of knowledge, attitudes and perceptions in the uptake of agricultural and agroforestry innovations among smallholder farmers in sub-Saharan Africa. Int J Agric Sustain. 2015;13:40-54.

37. FAO (2013). The Food Security Learning Framework the M\&E Harmonization Group of Food Security Partners.

\section{Publisher's Note}

Springer Nature remains neutral with regard to jurisdictional claims in published maps and institutional affiliations.
Ready to submit your research? Choose BMC and benefit from:

- fast, convenient online submission

- thorough peer review by experienced researchers in your field

- rapid publication on acceptance

- support for research data, including large and complex data types

- gold Open Access which fosters wider collaboration and increased citations

- maximum visibility for your research: over 100M website views per year

At BMC, research is always in progress.

Learn more biomedcentral.com/submissions 